\title{
Pyloroduodenal intussusception due to diffuse juvenile polyposis in a 3 year-old child: case report
}

\author{
Tutku Soyer $^{1 \oplus}$, Bilge Gördü ${ }^{1 \oplus}$, Özlem Boybeyi Türer ${ }^{1 \oplus}$, Berna Oğuz ${ }^{2 \oplus}$ \\ Departments of ${ }^{1}$ Pediatric Surgery and ${ }^{2}$ Pediatric Radiology, Hacettepe University Faculty of Medicine, Ankara, Turkey.
}

\begin{abstract}
Background. Pyloroduodenal intussusception (PDI) due to gastric and pyloric polyps is very rare and has not been reported previously in children.

Case. A 3 year-old boy was admitted with non-bilious vomiting and abdominal distention. Abdominal X-ray showed gastric air-fluid level and ultrasonography showed $5 \mathrm{~cm}$ intussusception at right upper quadrant. Upper gastrointestinal study showed gastric outlet obstruction. Multiple polyps at stomach and pylorus were detected in endoscopy. The explorative laparotomy revealed polyps originating from pylorus passing to duodenum and causing PDI. The polyps were excised to reduce the intussusception via duodenotomy.

Conclusion. PDI and pyloric polyps should be kept in mind in cases with radiological examinations revealing gastric outlet obstruction.
\end{abstract}

Key words: intussusceptions, pylorus, gastric outlet obstruction, polyps.

Juvenile polyps (JP) are epithelial or submucosal growths that protrude into the lumen of the bowel. They may cause bleeding, abdominal pain and intussusception. JP account $80 \%$ of all gastrointestinal polyps and the proximal colon is the most common localization. ${ }^{1}$ Children with diffuse juvenile polyposis are usually 6 months to 5 years of age and present with rectal bleeding, prolapsus, protein-losing enteropathy, intussusception and malnutrition. ${ }^{2}$ Polyps extrude into the bowel lumen may be propelled distally by peristalsis and may lead to intussusception. Gastrointestinal (GI) polyps account for $4 \%$ of all intussusceptions as a leading point in children. ${ }^{3}$ Pyloroduodenal intussusception (PDI) due to gastrointestinal tumors was reported in adults and has not been reported in children previously.

\section{Tutku Soyer \\ soyer.tutku@gmail.com}

Received 15th August 2019, accepted 15th September 2019.

The case was presented at National Congress of Pediatric Surgery Associations in 25-28 October 2017, Edirne, Turkey.
Intussusception can be idiopathic (without leading point), due to a leading point or can occur postoperatively. The incidence of intussusception caused by a leading point in an infant or a child ranges from $1.5 \%$ to $12 \%{ }^{4}$ Intestinal polyps are the most common cause of a leading point after Meckel's diverticulum. When classified into anatomic types, ileocolic intussusception is the most common (85\%). PDI is not reported and/or classified as 'others'. We aimed to present the first case of PDI in a 3 yearold children to discuss the clinical features and treatment options for this rare type of gastric outlet obstruction.

\section{Case Report}

The informed consent prior to the inclusion of the case was obtained from the family of the patient. A 3-year-old boy with allogeneic hematopoietic stem cell transplantation due to severe combined immune deficiency (SCID) and adenosine-deaminase deficiency was admitted with non-bilious vomiting and abdominal distention. In his past medical history, he underwent both upper and lower 
GI endoscopy because of bloody stool and was diagnosed with diffuse juvenile polyposis. He had protein-losing enteropathy and received intravenous immunoglobulin $\mathrm{G}$, albumin and enzyme replacement treatment.

At admission, his vital signs were within normal limits. Complete blood count findings showed hemoglobin $9.8 \mathrm{~g} / \mathrm{dl}$, neutrophils $8 \times 10^{3} \mathrm{~mm}^{3}$, and platelet count was $95 \times 10^{3} \mathrm{~mm}$. Liver and renal function tests were normal. The physical examination revealed epigastric distention and a palpable mass at epigastrium. Ultrasonography of abdomen showed $5 \mathrm{~cm}$ intussusception at right upper quadrant (Fig. 1). Upper GI study confirmed gastric outlet obstruction (Fig. 1). The patient was diagnosed with PDI and surgical treatment was suggested to reduce intussusception. Before explorative laparotomy, upper GI endoscopy was performed under anesthesia and multiple polyps originating from the stomach and pylorus were detected. The pyloric orifice was displaced and obstructed with polyps (Fig. 2). It was not possible to pass the endoscope through pylorus and examine the duodenum because of protruding polyps into the duodenum. Surgical exploration via right transverse incision revealed polyps originating from pylorus passing to duodenum and causing
PDI (Fig. 3). After transverse duodenotomy, polyps were excised and intussusception was reduced (Fig. 3). Since the gastrointestinal passage was obtained after polyp excision, there was no need for gastroduodenostomy. The postoperative period was uneventful and the histopathological evaluation of excised polyps confirmed diffuse juvenile polyposis of childhood. After the surgical treatment, the patient was followed-up for two years free of symptoms but died due to acute pulmonary thromboembolism at 5 years-of age.

\section{Discussion}

Diffuse JP of infancy present with multiple polyps in the entire GI tract in which stomach, distal colon and rectum are the most common localizations. Gastric polyposis protruding to pylorus and duodenum is seldom rare and reported in adults as a cause of gastroduodenal intussusceptions. ${ }^{5}$ Herein, we report the first pediatric case of PDI due to diffuse JP.

Gastroduodenal or pyloroduodenal polyps may be part of polyposis syndrome or due to prolonged use of proton pump inhibitors. ${ }^{6}$ Different from polyps, gastrointestinal tumors

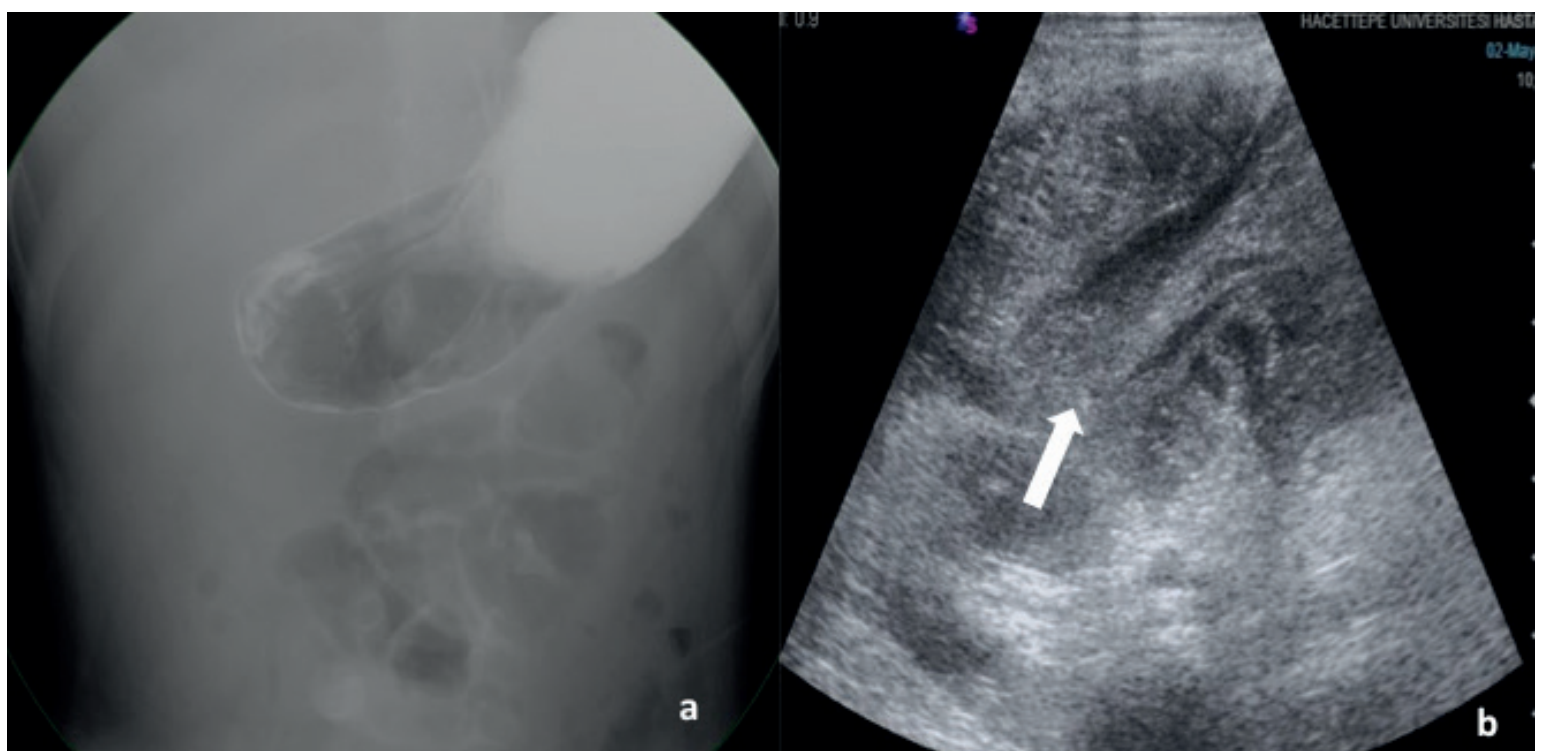

Fig. 1. Upper GI contrast graph showed gastric outlet obstruction (a). The ultrasonography showed target sign (arrow) and confirmed the diagnosis of PDI (b). 


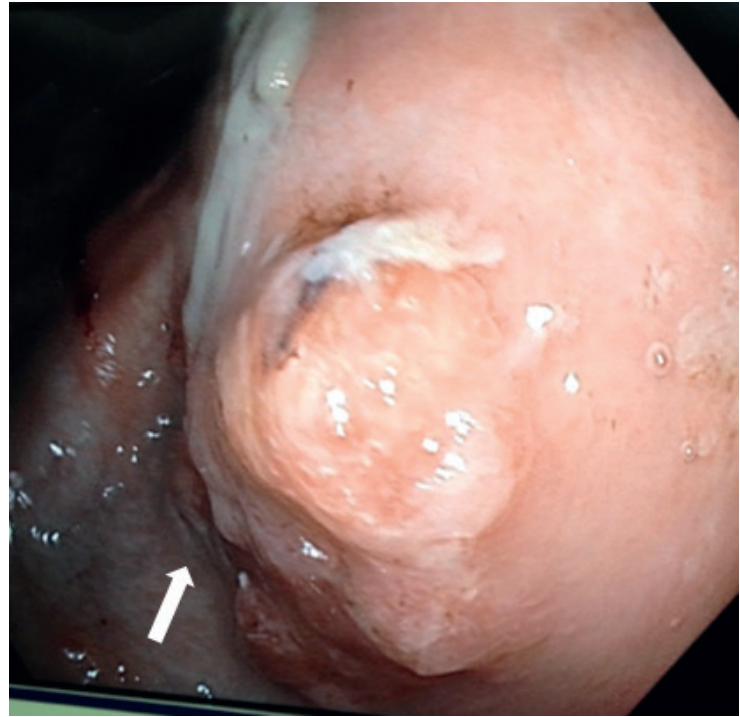

Fig. 2. The upper GI endoscopy showed gastric polyps. The pyloric orifice (arrow) was displaced and obstructed by polyps.

are a more common cause of gastroduodenal intussusception in adults and accounts for $10 \%$ of all adulthood intussusceptions. ${ }^{7}$ PDI is extremely rare because gastric cardia, pylorus and duodenum are much more secure and less mobile than the small and large bowel. Despite other intussusceptions, no idiopathic occurrence was reported for PDI and almost all of the cases had a leading point including tumors and polyps. Similar to adult cases, diffuse JP involving the pylorus was the cause of PDI in our patient. Although, no causative relation has been defined between adenosine deamianse deficiency and gastrointestinal polyposis, intercellular deposition of toxins due to elevated adenosine and 2'-deoxyadenosine can be suggested as a cause for diffuse JP in our patient.

PDI and gastroduodenal intussusceptions presents with non-bilious vomiting and gastric outlet obstruction. ${ }^{6}$ In addition, obstruction of pancreatic exocrine enzymes and bile due to displacement of surrounding tissues can be seen. The onset of symptoms is usually variable and a majority of patient's present acutely.? Episodic abdominal pain can be seen if the history is longstanding. Also, spontaneous reduction and recurrence of intussusception presents with cramped abdominal pain.

The diagnosis of PDI can be obtained by ultrasonography and typical target sign on the involved site reveals intussusception. Although contrast enema is both diagnostic and therapeutic in ileocolic and colonic intussusceptions, PDI requires upper GI contrast studies for diagnosis. The endoscopy of upper GI can be done not only for diagnosis but also for sampling of polyps for histopathological evaluations. In the current case, we confirmed the gastric outlet obstruction by contrast GI study. Additionally, it was not possible to pass the endoscope into the duodenum and the gastric outlet was fully obstructed by pyloric polyps. Computed tomography (CT) was used
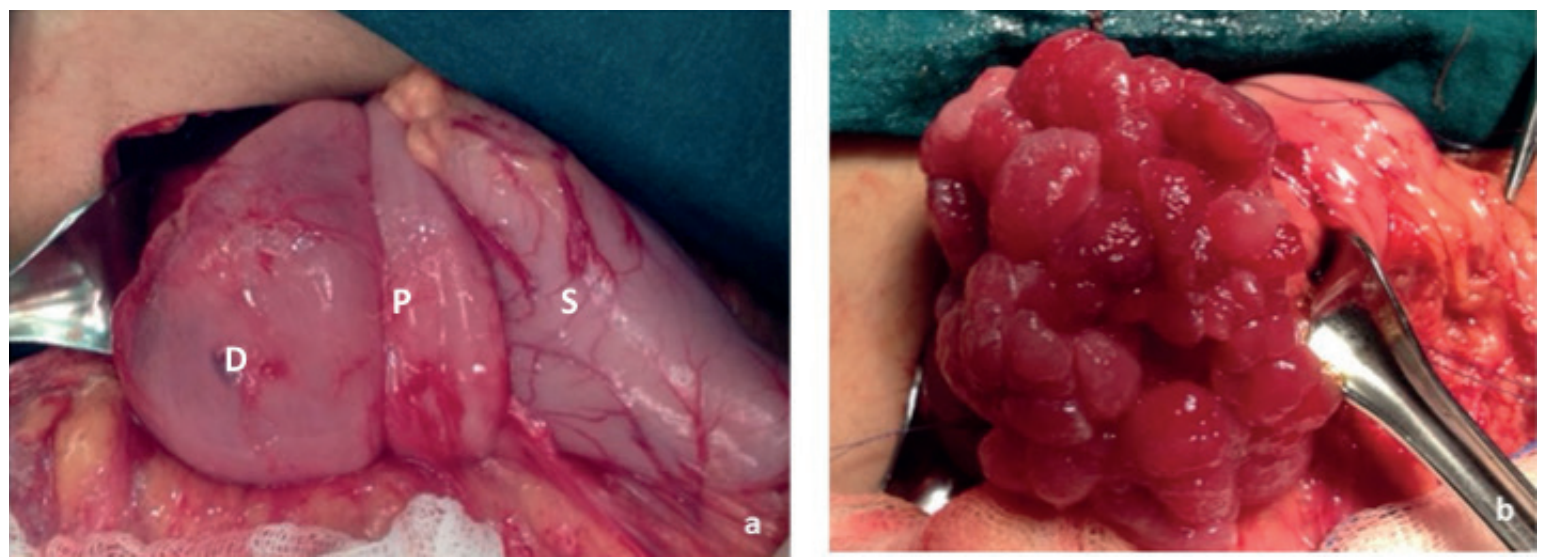

Fig. 3. The gross appearance of PDI (a). The surgical reduction of PDI and excision of polyps (b). (D: duodenum, P: pylorus, S: stomach). 
as the most reliable tool for diagnosis of PDI in adults. ${ }^{7}$ It is valid if tumor is suggested as a leading point. However, other radiologic interventions are adequate for diagnosis.

In the treatment of PDI, manual reduction of intussusception and surgical excision of polyps is recommended. In diffuse JP, multiple polyps obstructing the gastric outlet can be excised by duodenotomy or gastrotomy. We preferred to excised the polyps by incising the duodenum and exclude the other obstructing polyps in the distal duodenal segments. After excising all pyloric polyps, gastroduodenal passage was controlled and obstruction in the passage was eliminated. Gastroduodenostomy can be reserved for the patients, in case of inadequate polyp excision or if a clear gastroduodenal passage is not provided.

The outcome of our patient was eventful two years after the surgical treatment and followup endoscopies reveal no novel polyps in the stomach and pylorus. However, the patient died of pulmonary thromboembolism as a complication of SCID and adenosine deaminase deficiency.

In conclusion, PDI should be kept in mind as a cause of gastric outlet obstruction in patients who are admitted with non-bilious vomiting and abdominal distention. Infants with diffuse JP especially involving gastric antrum and pylorus may cause PDI and gastric outlet obstruction. Although surgical excision of the polyps is adequate in the treatment, gastroduodenostomy should be kept in mind if total excision of polyps is not possible.

\section{REFERENCES}

1. Mestre JR. The changing pattern of juvenile polyps. Am J Gastroenterol 1986; 81: 312-314.

2. Cobum MC, Pricolo VE, DeLuca FG, Bland KI. Malignant potential in intestinal juvenile polyposis syndromes. Ann Surg Oncol 1995; 2: 386-391.

3. Yalcin S, Ciftci AO, Karaagaoglu E, Tanyel FC, Şenocak ME. Presenting clinical features and outcome in intussusception. Indian J Pediatr 2009; 76: 401-405.

4. Navarro O, Deneman A. Intussusception Part 3: diagnosis and management of those with an identifiable or predisposing cause and those that reduce spontaneously. Pediatr Radiol 2004; 34: 305312.

5. Behrens S, Obando J, Blazer III DG. Gastric intussusception secondary to fundic gland polyposis. J Gastraintest Surg 2019; 23: 1073-1074.

6. Behrooz A, Cleasby M. Gastrogastric intussusception in adults: a case report with review of the literature. BJR Case Rep 2018; 4: 20180006.

7. Rittenhause DW, Lim PW, Shirley LA, Chonjnacki KA. Gastrodueodenal intussusception of a gastrointestinal stromal tumor (GIST): case report and review of the literature. Surg Laparosc Endosc Percutan Tech 2013; 23: e70-e73. 